\title{
Commentary: Duration of brain death and heart transplant outcomes: The devil is in the detail
}

\author{
Arman Kilic, MD
}

\author{
From the Division of Cardiac Surgery, University of Pittsburgh Medical Center, Pittsburgh, Pa. \\ Disclosures: Dr Kilic is on the Medical Advisory Board for Medtronic Inc. \\ Received for publication May 19, 2019; accepted for publication May 21, 2019; available ahead of print June 27, \\ 2019. \\ Address for reprints: Arman Kilic, MD, Division of Cardiac Surgery, University of Pittsburgh Medical Center, 200 \\ Lothrop St, Suite C700, Pittsburgh, PA 15213 (E-mail: kilica2@upmc.edu). \\ J Thorac Cardiovasc Surg 2020;159:1356 \\ $0022-5223 / \$ 36.00$ \\ Copyright (c) 2019 Published by Elsevier Inc. on behalf of The American Association for Thoracic Surgery \\ https://doi.org/10.1016/j.jtcvs.2019.05.023
}

Jawitz and colleagues ${ }^{1}$ present an analysis of the United Network for Organ Sharing Registry aiming to evaluate the association between duration of donor brain death and survival after heart transplant. Utilizing the advantages of a multicenter database, the authors demonstrate in 22,960 heart transplants that neither short nor prolonged duration of brain death influences posttransplant survival. The 10-year survival is nearly identical when stratified according to short ( $<22$ hours), reference (22-42 hours) or long ( $>42$ hours) duration of brain death at $61.3 \%$, $61.8 \%$, and $61.1 \%$, respectively.

The physiologic effects of brain death on a potential organ donor are well documented. Increases in intracranial pressure can lead to brain stem herniation and bradycardia with a resultant catecholamine surge. ${ }^{2}$ This cascade can manifest as hemodynamic instability.

So, what are the possible mechanisms by which duration of brain death would have an influence on posttransplant survival? It can be argued that longer periods of brain death can subject the donor to the continued risk of hemodynamic instability with adverse, incremental effect on organ quality. Or, the opposite argument would be that longer periods of time could allow for active management of the donor and correction of any deleterious effects of brain death, in addition to more time to recover from the catecholamine surge.

An essential outcome missing from the current analysis by Jawitz and colleagues ${ }^{1}$ is primary graft dysfunction. In multiple prior analyses, longer durations of donor brain death were found to correlate with reduced risk of primary graft failure. ${ }^{3,4}$ Unfortunately, primary graft dysfunction is not recorded in the United Network for Organ Sharing database and the authors were unable to assess this association.

Another important aspect relates to the proportion of potential donors who were declined. Without these data,

\section{References} 159:1345-53.e2. 1352-9. 33-7. 2168-71.

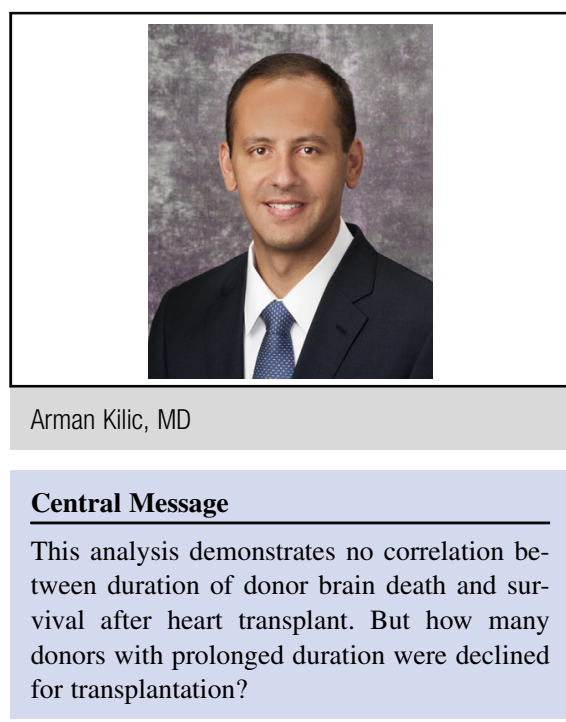

See Article page 1345 .

the study is subject to selection bias. For example, if only $1 \%$ of donor organs with a duration of brain death $>42$ hours were utilized compared with $50 \%$ in the $<22$-hour duration group, this clearly suggests that the prolonged cohort was much more highly selected. Nonetheless, the current report does add to our understanding of donor selection and suggests that duration of brain death alone should not be used as the sole criteria for acceptance or rejection of a potential donor.

1. Jawitz OK, Raman V, Barac YD, Anand J, Patel CB, Mentz RJ, et al. Influence of donor brain death duration on outcomes following heart transplantation: a United Network for Organ Sharing Registry analysis. J Thorac Cardiovasc Surg. 2020;

2. Chen EP, Bittner HB, Kendall SW, Van Trigt P. Hormonal and hemodynamic changes in a validated animal model of brain death. Crit Care Med. 1996;24:

3. Marasco S, Kras A, Schulberg E, Vale M, Chan P, Lee GA, et al. Donor brain death time and impact on outcomes in heart transplantation. Transplant Proc. 2013;45:

4. Quintana-Quezada RA, Rajapreyar I, Postalian-Yrausquin A, Yeh YC, Choi S, Akkanti B, et al. Clinical factors implicated in primary graft dysfunction after heart transplantation: a single-center experience. Transplant Proc. 2016;48: 